\title{
Applications of the Carrier Free Radioisotopes of Second Transition Series Elements in the Field of Nuclear Medicine
}

\author{
Banani Mukhopadhyay ${ }^{1 *}$ and Krishnendu Mukhopadhyay ${ }^{2 *}$
}

${ }^{1}$ Assistant Professor, Department of Chemistry, Women's Christian College, College Road, Chennai 600006 , India

${ }^{2}$ Assistant Professor, Department of Environmental Health Engineering, Sri Ramachandra University, Porur, Chennai 600 116, India

\begin{abstract}
The carrier free radioisotopes play a vital role in the rapidly emerging fields of science and technology, emphatically in the areas of biomedical sciences. Again, the carrier free radioisotopes of transition series elements have achieved special importance due to their favourable nuclear and chemical properties, either in material research or in biomedical applications. In the present review article, the beneficial uses of some carrier free radioisotopes of the second transition series elements such as ${ }^{90} \mathrm{Y},{ }^{89} \mathrm{Zr},{ }^{97,103} \mathrm{Ru},{ }^{99 \mathrm{~m}} \mathrm{Tc},{ }^{101 \mathrm{~m}} \mathrm{Rh},{ }^{111} \mathrm{Ag},{ }^{107,109} \mathrm{Cd}$, etc. in the field of nuclear medicine has been discussed. Some probable routes for production of these radionuclides have also been indicated.
\end{abstract}

Keywords: Carrier free; Radioisotopes; Transition series; Biomedical; ${ }^{90} \mathrm{Y} ;{ }^{89} \mathrm{Zr} ;{ }^{97,103} \mathrm{Ru} ;{ }^{99 \mathrm{~m}} \mathrm{Tc}$

\section{Introduction}

In 1934, the remarkable discovery of artificial radioactivity by Irene and Frederic Joliot Curie had added the most important step in the journey of nuclear medicine. Initially, the production of the artificial radioisotopes was slow but, gradually it enhanced the pace by producing more than 2500 radioisotopes till now through nuclear transmutation reactions. Visualization of organs, localisation of tumours, detection of abnormalities in diagnosis, determination of metabolic pathways, introduction of radiation sources into specific sites for therapy are the different goals of nuclear medicine[1]. This can involve either the direct irradiation of the patients by an external source of radiation, or the administration of radioactively labeled drugs or radiopharmaceuticals to the patient.

The word "pharmaceutical" is related to "pharmakon", which means poison or medicine. Usually depending upon the dosage sometimes a drug may act as a poison or as a medicine in a biological system [2]. The radiopharmaceuticals are chemical compounds containing the appropriate radioactive isotopes or radionuclides which are rendered suitable for human administration. There are certain specific criteria for a radionuclide to be used in nuclear medicine. The radionuclides having suitably short half lives and a high yield of gamma rays are used for radiopharmaceutical preparation.

The basic aim in designing radiolabeled compounds for therapy is to create a high concentration of radioactivity in the target tissues. It should be capable of delivering the desired radiation dose with minimal exposure to not-target tissue of the remainder portion of the body. Bone marrow is a very important not-target tissue. Actually to avoid excessive tissue irradiation from other emissions, e.g., from high energy $\beta$-particles during the administration of radiopharmaceuticals in living body, they are prepared with high specific activity so that a small volume is administered. High specific activity of the radioisotopes will be achieved when they are prepared in carrier Free State.

Another important point regarding the applications of radiopharmaceuticals is that the radiation dose depend both on the physical characteristics of the radionuclides and biological behavior of the radiopharmaceuticals. In other words the amount of time that a drug is useful depends on both its radioactive half-life and biological half-life.
Again, almost all the elements of transition series have more than one radioisotope having intense $\gamma$ energy peaks in the detectable energy region within a wide range of half lives. The rich chemistry of the Transition Series elements, specially their variable oxidation states, ability to form various types of complexes with almost all types of ligands, is useful for making numerous radiolabeled compounds. Conjunction of these physical and chemical properties made the carrier free radionuclides of Transition Series elements almost indispensable to medical sciences especially for in vivo applications.

Keeping these facts in mind in the present review article applications of some of the carrier free radioisotopes of Second Transition Series elements such as ${ }^{90} \mathrm{Y},{ }^{89} \mathrm{Zr},{ }^{97,103} \mathrm{Ru},{ }^{99 \mathrm{~m}} \mathrm{Tc},{ }^{101 \mathrm{~m}} \mathrm{Rh},{ }^{111} \mathrm{Ag},{ }^{107,109} \mathrm{Cd}$, etc. in the field of nuclear medicine have been discussed. Again few important applications of these radioisotopes are also given in a very concise form (Table 1). Some probable production routes of these radionuclides have also been indicated in a tabular form (Table 2).

\section{Radioisotopes of yttrium}

The carrier-free ${ }^{90} \mathrm{Y}$ isotope has been investigated as potentially useful therapeutic radioisotope in nuclear medicine. Radiation synovectomy has been pursued for a number of years as an effective alternative to chemical and surgical synovectomy for treatment of arthritis [3]. Its aim is to reduce the pain, improve mobility and preserve joint function, resulting in better quality of life for the patient. Because of its favourable physical characteristics, ${ }^{90} \mathrm{Y}$ is used in radiation synovectomy, for treatment of rheumatoid arthritis [4]. It

*Corresponding authors: Banani Mukhopadhyay, Assistant Professor Department of Chemistry, Women's Christian College, College Road, Chennai 600 006, India, Tel: +91 94447979 71; E-mail: banalata97@rediffmail.com

Krishnendu Mukhopadhyay, Assistant Professor, Department of Environmental Health Engineering, Sri Ramachandra University, Porur, Chennai 600116 India, Tel: +91 994100 5563, Fax: +91 44 24767008; E-mail: krishnendu. mukhopadhyay@gmail.com

Received February 21, 2011; Accepted July 23, 2011; Published July 25, 2011

Citation: Mukhopadhyay B, Mukhopadhyay K (2011) Applications of the Carrier Free Radioisotopes of Second Transition Series Elements in the Field of Nuclear Medicine. J Nucl Med Radiat Ther 2:115. doi:10.4172/2155-9619.1000115

Copyright: (C) 2011 Dalhaug A, et al. This is an open-access article distributed under the terms of the Creative Commons Attribution License, which permits unrestricted use, distribution, and reproduction in any medium, provided the original author and source are credited. 
Citation: Mukhopadhyay B, Mukhopadhyay K (2011) Applications of the Carrier Free Radioisotopes of Second Transition Series Elements in the Field of Nuclear Medicine. J Nucl Med Radiat Ther 2:115. doi:10.4172/2155-9619.1000115

Page 2 of 9

\begin{tabular}{|c|c|c|c|c|c|c|}
\hline $\begin{array}{l}\text { Radio- } \\
\text { nuclides }\end{array}$ & Chemical Nature & Half life & Decay Mode & $\begin{array}{l}\text { Principal y energy } \\
\text { (keV) (Intensity \%) }\end{array}$ & Applications & References \\
\hline \multirow[t]{2}{*}{${ }^{90} \mathrm{Y}$} & & $64.1 \mathrm{~h}$ & & - & $\begin{array}{l}\text { Radioimmunotherapy of cancer, adjuvant to chemotherapy and } \\
\text { bone seeking agent for bone marrow ablation }\end{array}$ & 6 \\
\hline & DTPA & & & & Intra-vascular radionuclide therapy (IVRANT) & 8 \\
\hline${ }^{89} \mathrm{Zr}$ & & $78.4 \mathrm{~h}$ & & $909.1(99.01 \%)$ & Antibody labelling and PET imaging & 13 \\
\hline \multirow[t]{13}{*}{${ }^{99 \mathrm{~m}} \mathrm{Tc}$} & & $6.01 \mathrm{~h}$ & IT, $\beta-0.004$ & $140.5(87.2 \%)$ & SPET and labelling of leucocytes & 59 \\
\hline & CAP & & & & $\begin{array}{l}\text { Monitoring of progression or regression of tumor during radiation } \\
\text { therapy }\end{array}$ & 48 \\
\hline & Apcitide & & & & Detection of acute deep vein thrombosis & 49 \\
\hline & Tetra- cycline & & & & Detection of infarcts and determination of its size & 24 \\
\hline & Bleo-mycin & & & & Scintigraphic visualisation of malignant tumours & 29 \\
\hline & DTPA & & & & Scintigraphy of kidney & 31 \\
\hline & Stannous phylate & & & & Hepatic imaging agent & 32 \\
\hline & Sulfide colloid & & & & Liver spleen scanning agent & 33 \\
\hline & $\begin{array}{l}\text { Tetro- } \\
\text { fosmin }\end{array}$ & & & & Myocardial perfusion imaging and tumor seeking agent & 22 \\
\hline & $\mathrm{MIBI}$ & & & & Imaging of myocardium & 72 \\
\hline & Fosfo-mycin & & & & Renal agent & 53 \\
\hline & HAS & & & & Static and dynamic imaging of vascular spaces & 65 \\
\hline & Penicilla-mine & & & & Potentially useful cholescintigraphic agents & 68 \\
\hline \multirow[t]{2}{*}{${ }^{103} \mathrm{Ru}$} & & $39.26 d$ & $\beta$ & $497.05(88.7 \%)$ & Scintigraphy of patients with various types of malignant tumours & 83 \\
\hline & Ruthenium Red & & & & $\begin{array}{l}\text { Employed in histochemistry due to its affinity towards } \\
\text { mucopolysaccharides and tumour scanning agent }\end{array}$ & 83 \\
\hline \multirow[t]{6}{*}{${ }^{97} \mathrm{Ru}$} & DTPA & $2.9 \mathrm{~d}$ & $\varepsilon$ & $215.70(86.0)$ & Cerebrospinal fluid imaging agent & 82 \\
\hline & PIPIDA & & & & Hepatobiliary diagnostic agent & 77 \\
\hline & Mono-clonal antibodies & & & & Radioimmunotherapy & 76,78 \\
\hline & Bleo-mycin & & & & Cancer chemotherapeutic agent & 79 \\
\hline & Trans-ferrin & & & & Diagnosis of tumours & 79 \\
\hline & DISIDA & & & & Liver Imaging & 81 \\
\hline${ }^{111} \mathrm{Ag}$ & & $7.45 d$ & $\beta-$ & $342.08(6.7)$ & Radioimmunotherapy & 93 \\
\hline${ }^{109} \mathrm{Cd}$ & & $462 d$ & $\varepsilon$ & $88.03(3.6)$ & $\begin{array}{l}\text { Source of } x \text { - radiation, } \\
\text { Long term metabolic studies }\end{array}$ & 96,97 \\
\hline${ }^{107} \mathrm{Cd}$ & & $6.50 \mathrm{~h}$ & $\varepsilon$ & $93.1(4.7)$ & Short term metabolic studies & 97 \\
\hline
\end{tabular}

Table 1: Applications of various radionuclides of Second Transition Series elements in Nuclear Medicine.

\begin{tabular}{|c|c|c|}
\hline Radionuclide & Source/Production Route & Reference \\
\hline${ }^{89} \mathrm{Zr}$ & $\begin{array}{l}\text { Proton irradiation of natural yttrium: }{ }^{89} \mathrm{Y}(\mathrm{d}, 2 \mathrm{n})^{89} \mathrm{Zr} \\
\alpha \text {-activation of natural yttrium: }{ }^{89} \mathrm{Y}(\alpha, \mathrm{p} 3 \mathrm{n}){ }^{89} \mathrm{Zr}\end{array}$ & $\begin{array}{l}101 \\
102\end{array}$ \\
\hline${ }^{90} \mathrm{Y}$ & $\beta$ - decay of ${ }^{90} \mathrm{Sr}:{ }^{90} \mathrm{Sr} \stackrel{\beta}{\longrightarrow}{ }^{90} \mathrm{Y}$ & 103 \\
\hline
\end{tabular}

Table 2: Routes of production of some carrier free radioisotopes of Second Transition Series elements.

has a half life of $64.1 \mathrm{~h}$ and decays to the stable ${ }^{90} \mathrm{Zr}$ daughter product, by emission of high energy $\beta$ radiation $\left(\mathrm{E}_{\max }=2.28 \mathrm{MeV}\right)$. The beta rays have a maximum tissue range of $11 \mathrm{~mm}$ which is useful for the treatment of large joints such as the knees. Another major advantage is the availability of ${ }^{90} \mathrm{Y}$ from a ${ }^{90} \mathrm{Sr} /{ }^{90} \mathrm{Y}$ generator, since the $28.8 \mathrm{yr}$ half life of ${ }^{90} \mathrm{Sr}$ makes it an attractive generator system for long-term usage [5]. ${ }^{90} \mathrm{Y}$ is employed in raddioimmunotherapy of cancers for site specific monoclonal antibody labeling [6]. ${ }^{90} \mathrm{Y}$ obtained from a ${ }^{90} \mathrm{Sr}$ generator, adsorbed onto resin bed has been evaluated as an adjuvant to chemotherapy [7]. Dosimetric considerations have been made on ${ }^{90} \mathrm{Y}$ radionuclide which could be incorporated into a bone seeking agent for bone marrow ablation. ${ }^{90} \mathrm{Y}-1,4,7,10$-tetraazacyclododecane tetraacetic acid $\left({ }^{90} \mathrm{Y}\right.$-DOTA) and ${ }^{90} \mathrm{Y}$-diethylene triamine pentaacetic acid $\left({ }^{90} \mathrm{Y}\right.$-DTPA) complexes were studied for possible use in intravascular radionuclide therapy (IVRNT). Biodistribution of these complexes in Swiss mice showed that nearly $90 \%$ of ${ }^{90} \mathrm{Y}$ complexes of both the ligands were excreted via urine predominantly through glomerular filtration within one hour post-injection with negligible localization in vital organs. The predominant and quick excretion of ${ }^{90} \mathrm{Y}$-DOTA and ${ }^{90} \mathrm{Y}$-DTPA through the kidneys suggest that both these complexes could be explored for use in IVRNT [8]. The ${ }^{90} \mathrm{Y}$-citrate is used in the biologic dosimetry of bone marrow ${ }^{(9) . ~}{ }^{90} \mathrm{Y}$-ibritumomab tiuxetan is a novel radio immunotherapeutic agent recently approved for the treatment of relapsed or refractory low grade, follicular, or $\mathrm{CD} 20+$ transformed non-Hodgkin's lymphoma. ${ }^{90} \mathrm{Y}$-ibritumomab tiuxetan consists of a murine monoclonal antibody covalently attached to a metal chelator, which stably chelates ${ }^{111}$ In for imaging and ${ }^{90} \mathrm{Y}$ for therapy [10].

Though the carrier free ${ }^{90} \mathrm{Y}$ radioisotope is widely used for therapeutic purposes it can not be used for imaging. Consequently some reports described attempts to use $\gamma$-emitting yttrium isotopes $\left({ }^{87} \mathrm{Y},{ }^{86} \mathrm{Y}\right)$ to quantify the biodistribution of $\mathrm{Y}$ pharmaceuticals in animals as well as in humans[11]. Quantitative regional kinetics can be studied by positron emission tomography (PET). The neutron deficient ${ }^{86} \mathrm{Y}$ radioisotope, a relatively long-lived positron emitter appears to be most promising for such PET studies [12].

\section{Radioisotopes of zirconium}

Whole body distribution and time course of diagnostic or 
therapeutic immuno-conjugates can be obtained noninvasively using Positron Emission Tomography (PET) and a suitable positron emitting antibody. This pharmacokinetic information can then be used to perform dosimetric calculations in order to optimize procedures involving these immuno-conjugates. Since the clearance rates of most immuno-conjugates are relatively slow, good target to blood ratios are not achieved until $24 \mathrm{~h}$ or more after administration. Thus, commonly used PET radioisotopes, notably ${ }^{18} \mathrm{~F}\left(\mathrm{~T}_{1 / 2}=110 \mathrm{~m}\right)$ and ${ }^{68} \mathrm{Ga}\left(\mathrm{T}_{1 / 2}=68 \mathrm{~m}\right)$, may not be suitable as antibody labelers. ${ }^{89} \mathrm{Zr}$ was first proposed and evaluated by Link et al. (1986) as PET antibody label since its halflife $(78 \mathrm{~h})$ is appropriate and the chemistry to attach this metal ion to antibodies using DTPA linkages is straightforward [13]. Furthermore, production of ${ }^{89} \mathrm{Zr}$ via $(\mathrm{p}, \mathrm{n})$ reaction on ${ }^{89} \mathrm{Y}(100 \%$ natural abundance) can be done using cyclotrons available to all PET centers [14].

\section{Radioisotopes of technetium}

The ${ }^{99} \mathrm{Mo} /{ }^{99 \mathrm{~m}} \mathrm{Tc}$ generators have wider applications in diagnostic nuclear medicine. The generator elutes contain not only ${ }^{99 \mathrm{~m}} \mathrm{Tc}$ but also the long lived beta emitter ${ }^{99} \mathrm{Tc}$ [15]. At present carrier free ${ }^{99 \mathrm{~m}} \mathrm{Tc}$ radioisotope is used for more than $90 \%$ diagnostic procedures. It has multipurpose medicinal applications. During the past two decades it is serving as the backbone of nuclear medicine. Now the radiotracer ${ }^{99 \mathrm{~m}} \mathrm{Tc}$ has acquired its important position in the diagnostic nuclear medicine due to its ideal photon energy $(140 \mathrm{keV})$, half-life $(6.02 \mathrm{~h})$ and availability. Recently, great attempts are being taken to synthesize ${ }^{99 \mathrm{~m}} \mathrm{Tc}$ labeled radiopharmaceuticals to monitor the metabolic function of the brain and heart.

The preparation of ${ }^{99 \mathrm{~m}} \mathrm{Tc}$-labelled radiopharmaceuticals generally requires the initial reduction of ${ }^{99 m} \mathrm{Tc}$-pertechnetate, followed by reaction with added complexing agents. For this procedure, the reducing agent must be non-toxic, water soluble and must suppress ${ }^{99 \mathrm{~m}} \mathrm{Tc}$-colloid formation. The use of cuprous ion as a reducing agent for pertechnetate was described for the first time by Chervu et al. The potential usefulness of a ${ }^{99 \mathrm{~m}} \mathrm{Tc}-\mathrm{Cu}$-DTPA complex as a renal function agent was evaluated by organ distribution studies in animals and by simultaneous continuous-infusion and single injection clearance studies. Dialysis of plasma samples obtained after the injection of ${ }^{99 \mathrm{~m}} \mathrm{Tc}-\mathrm{Cu}-\mathrm{DTPA}$ into bilaterally nephrectomized rats indicates that only small amounts $(<4 \%)$ of the complex are protein bound. This observation and the low toxicity of the copper preparation in animals appear to justify its investigation for kidney function measurement and imaging in man as well as its use as a GFR agent in animal studies [16].

The lipophilic complex of Technetium i.e., $\left[{ }^{99 \mathrm{~m}} \mathrm{TcO}\right.$ (L)] (where $\mathrm{L}=3,6,6,9$-tetramethyl-4,8-diazaundecane-2,10-dione dioximate) is used as a cerebral blood flow imaging agent[17]. The radiopharmaceuticals currently being used for brain perfusion studies are the ${ }^{99 \mathrm{~m}} \mathrm{Tc}$ complexes of the tetradentate ligands hexamethyl propylene amineoxime (HMPAO) [18] and ethyl cysteinate dimmer (ECD) [19]. Both the ligands form neutral and lipophilic complexes with ${ }^{99 \mathrm{~m}} \mathrm{Tc}$ possessing an oxotechnetium core. The lipophilicities of the ${ }^{99 \mathrm{~m}} \mathrm{Tc}$ complexes are conductive features which enable them to cross the blood brain barrier [20]. Polycystic kidney disease is a common hereditary disease. One of the commonest complications of this disease is infection of the renal cysts. Conventional radiology, ultrasound and CT scan is not able to clearly localize the site of infection. But it has been found that Tc-99m HMPAO labeled leukocyte scan can

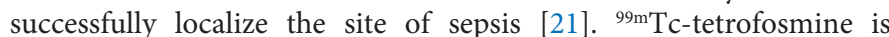
another lipophilic cationic complex that has been approved by the Food and Drug Administration as a myocardial perfusion imaging radiopharmaceutical. It has also been used as a tumour seeking agent. However its role in detecting lymphomas has not been widely investigated. Recently, Ding et al. have studied that ${ }^{99 \mathrm{~m}} \mathrm{Tc}$ tetrofosmin accumulated in the three tested lymphoma cell lines, with the greatest uptake in the Hodgkin's disease cell line. However, in comparison with ${ }^{99 \mathrm{~m}} \mathrm{Tc}$ sestamibi, ${ }^{99 \mathrm{~m}} \mathrm{Tc}$ tetrofosmin may not be the best radiotracer for detection of lymphoma [22]. The ${ }^{99 \mathrm{~m}} \mathrm{Tc}$-tetrofosmin chest images are potential tools for understanding multidrug resistance-mediated P-glycoprotien (MDR-Pgp) expression in nonsmall cell lung cancer and for predicting the chemotherapeutic response to paclitaxel [23].

The use of technetium labeled radiopharmaceutical like ${ }^{99 \mathrm{~m}} \mathrm{Tc}-$ tetracycline and ${ }^{99 \mathrm{~m}} \mathrm{Tc}$-pyrophosphate which are sequestered by acutely infarcted myocardium is discussed as a direct means of detecting an infarct and determining its size [24]. The polypeptide antibiotic drug, bleomycin [25] was recently found to have considerable therapeutic effects against epidermoid carcinomas and malignant lymphomas [26]. The polypeptide nature of bleomycin offers a unique possibility for labeling an antineoplastic drug with technetium. Such polypeptides as albumin [27] and caseidin [28] have been labeled with technetium. A trial study was undertaken to evaluate the bleomycin as a potential carrier of ${ }^{99 \mathrm{~m}} \mathrm{Tc}$ for scintigraphic visualization of malignant tumors [29]. Dimercaptosuccinate has been labelled with ${ }^{99 \mathrm{~m}} \mathrm{Tc}$ pertechnetate for imaging renal cortical morphology [30]. The conventional ${ }^{131}$ I-Hippuran renogram, measured with external detectors has the disadvantage of potential misinterpretation due to incorrect placement of the detectors. The problem of localising the kidneys for measurement of time activity curve corresponding to the kidney can be solved by recording curves from scintillation camera light-pen "areas of interest". This can be done with ${ }^{131}$ I-Hippuran. Iodine-131 however is not an ideal emitter for detailed imaging with the scintillation camera due to its relatively high energy gamma radiation (Main gamma energy $364 \mathrm{keV}$ ). ${ }^{99 \mathrm{~m}} \mathrm{Tc}$ is optimal for scintillation camera imaging, and ${ }^{99 \mathrm{~m}} \mathrm{Tc}$-DTPA provides detailed scintigrams of the kidney [31]. In 1973, Subramanian et al. introduced ${ }^{99 \mathrm{~m}} \mathrm{Tc}$-labelled stannous phylate as a hepatic imaging agent. The intravenously administersd ${ }^{99 \mathrm{~m}} \mathrm{Tc}-\mathrm{Sn}$-phylate forms an insoluble calcium salt in vivo and is actively deposited in the reticuloendothelial system, of which the hepatic Kupffer cell is the major component [32]. ${ }^{99 \mathrm{~m}} \mathrm{Tc}$-sulfide colloid has potential applications in liver spleen scan during the diagnosis of childhood sarcoidosis [33]

In order to understand the interaction of metal ions with proteins, antibodies and biocatalytic processes some research works have been reported showing the synthesis and characterisation of ${ }^{99} \mathrm{Tc}$ nitrido complexes with cysteine (CYS), cysteine ethyl ester (CYS-OEt), etc. The presence of the $\mathrm{T} c \equiv \mathrm{N}$ core in the structure may induce different physicochemical properties compared to the $\mathrm{TcO}$ species, especially as far as lipophililicity is concerned [34]. The ${ }^{99 \mathrm{~m} T \mathrm{Tc} \text { nitrido complex }}$ [99m TcN (CBDTC) $\left.{ }_{2}\right]$ (CBDTC: N-cyclobutyl dithiocarbamato) containing $\left[{ }^{99 \mathrm{~m}} \mathrm{TcN}\right]^{2+}$ core exhibited significant brain localization and good retention in mice, suggesting its potentiality as a brain perfusion imaging agent [35]. Biodistribution of a similar type of nitrido complex of ${ }^{99 \mathrm{~m}} \mathrm{Tc}$ [ ${ }^{99 \mathrm{~m}} \mathrm{TcN}$ (MECHDTC) ${ }_{2}$ (MECHDTC: N-methyl, N-cyclohexyl dithiocarbamato) in mice showed that the complex accumulated in the heart and brain with high uptake suggesting its use as potential myocardial and cerebral imaging agent [36]. The technetium-labelled$\mathrm{N}$-substituted iminodiacetate compounds have been used extensively in the last 15 years to evaluate whether a jaundiced patient has intrahepatic cholestasis or extra hepatic obstruction [37]. Recently, some authors have proposed the uses of these agents, especially diisopropyliminodiacetic acid (DISIDA), for the evaluation of different aspects of hepatic and intestinal function, e. g., for intestinal mortility [38], gallblader emptying [39], diagnosis of segmental biliary 
obstruction [40], etc. The ${ }^{99 \mathrm{~m}} \mathrm{Tc}$ pentavalent dimercaptosuccinic acid [99m Tc (V)DMSA] is a useful agent for imaging thyroid medullary carcinoma [41]. On the other hand, the ${ }^{99 \mathrm{~m} T \mathrm{TCN}-D M S A}$ complex would be potentially useful as a bone imaging agent which is reflected from its biodistribution in mice. Actually the biodistribution comparison in mice of the ${ }^{99 \mathrm{~m}} \mathrm{TcN}-\mathrm{DMSA}$ complex and ${ }^{99 \mathrm{~m}} \mathrm{Tc}$-DMSA complex indicate that the presence of the ${ }^{99 \mathrm{~m}} \mathrm{Tc}$ nitrido group significantly alters the biological properties of the ${ }^{99 \mathrm{~m}} \mathrm{Tc}$ complex [42].

Again the generator produced radionuclide ${ }^{99 \mathrm{~m}} \mathrm{Tc}$ is one of the most important radioisotopes used in Single Photon Emission Tomography (SPET). By virtue of their $\beta^{+}$decay the neutron deficient isotopes ${ }^{92} \mathrm{Tc}$ $\left(\mathrm{T}_{1 / 2}=4.4 \mathrm{~m}\right),{ }^{93 \mathrm{~g}} \mathrm{Tc}\left(\mathrm{T}_{1 / 2}=2.7 \mathrm{~h}\right),{ }^{94 \mathrm{~g}} \mathrm{Tc}\left(\mathrm{T}_{1 / 2}=4.88 \mathrm{~h}\right)$ and ${ }^{94 \mathrm{~m}} \mathrm{Tc}\left(\mathrm{T}_{1 / 2}=52 \mathrm{~m}\right)$ could be used in Positron Emission Tomography (PET). The radiopharmaceuticals containing the above mentioned radioisotopes of technetium allows one to get in-vivo biokinetic data, not accessible via the ${ }^{99 \mathrm{~m}} \mathrm{Tc}$-SPET technique [43]. To quantify the biodistribution of ${ }^{99 m} \mathrm{Tc}$ labeled radiopharmaceuticals in humans, it would be meaningful to combine SPECT and PET by using a positron emitting technetium isotope for the corresponding PET measurements. Taking advantage of the modern PET technique, the data obtained on the quantification of uptake kinetics and their mechanism would allow a better estimate of the diagnostic potential of new [ $\left.{ }^{99 \mathrm{~m}} \mathrm{Tc}\right]$-compounds. Furthermore it should be possible to quantify models on the metabolic pathways of already established [ ${ }^{99 \mathrm{~m}} \mathrm{Tc}$ ]-radiopharmaceuticals [44]. In a recent study, Groshar et al. attempted to asses the diagnostic performance of quantitative SPECT of ${ }^{99 \mathrm{~m}} \mathrm{Tc}$-phytate colloid in detecting liver cirrhosis and to asses the correlation between the SPECT results and the severity of disease. For this purpose quantitative SPECT was performed on 60 patients with liver cirrhosis and 36 control patients without liver cirrhosis and the results for the two groups were compared. Cirrhotic livers had a lower total uptake than did control livers. This reduced uptake was associated with a significantly reduced percentage injected dose per cubic centimeter. The volume was similar to that of control livers. Total uptake in the spleen was significantly greater in patients with cirrhosis than in control patients because of an increased volume. Finally they have concluded that individual SPECT quantification of ${ }^{99 \mathrm{~m}} \mathrm{Tc}$-phytate colloid uptake in the liver and spleen could be used as a noninvasive method to separate normal from cirrhotic livers and to evaluate the severity of disease [45]. Dopamine is one of the key neurotransmitters and is related to brain function, including movement, emotion and cognition. Dopamine transporters (DATs), which locate on presynaptic dopamine neuron terminals, modulate dopamine concentration in the synaptic cleft by pumping dopamine back to the presynaptic neurons. DAT is considered to be a marker for the functional integrity of dopamine neurons. Many radiolabeled tropane derivatives, which can specifically bind to DAT, have been prepared and studied for in vivo imaging of DAT with PET or SPECT. [99m Tc] TRODAT-1 (2 $\beta$-((N, N/bis (2-mercaptoethyl)ethylene diamino) methyl), $3 \beta$-(4-chlorophenyl)tropane) is the first ${ }^{99 \mathrm{~m}} \mathrm{Tc}$-labeled imaging agent to show specific binding to DAT in the striatum of the human brain and has been demonstrated successfully for the diagnosis of DAT deficiency in neurodegenerative disorders, such as Parkinson's disease [46].

Hematoporphyrin derivative $(\mathrm{HpD})$ and other porphyrins have been shown to accumulate in tumours. A new water soluble cyclam acid porphyrins (CAP), 5,10,15,20-tetrakis [ 4 - $\left\{4^{\prime}, 8^{\prime}, 11^{\prime}\right.$-tris(carboxymethyl)$1^{\prime}-\left(1^{\prime} 4^{\prime}, 8^{\prime}, 11^{\prime}\right.$-tetraazacyclotetradecane)amidomethyleneoxy $\}$ phenyl] porphyrin has been synthesized, characterized and labelled with ${ }^{99 \mathrm{~m}} \mathrm{Tc}$ [47]. In vivo distribution studies were performed in $\mathrm{C}_{6}$-gliomas and $\mathrm{N}$-nitroso-N-methylurea (NMU) induced mammary tumor bearing rats. Such types of studies revealed that the ${ }^{99 \mathrm{~m} T c-C A P}$ has potential for detection of cancer. In addition to the use of radiolabeled CAP for detection of tumors, this agent could be employed to monitor the progression or regression of tumors following many treatment protocols before, during and after chemotherapy or radiation therapy. Like monoclonal antibodies peptides are also receptor specific Radiolabeled receptor-specific biomolecules can detect primary sites, identify occult metastatic lesions, guide surgical intervention, stage tumors, predict efficacy of certain therapeutic agents or, when labeled with suitable radionuclides, be useful radiotherapeutic agents. During the past few years, much attention has been paid to the diagnostic applications of radiolabeled peptides. The carrier free ${ }^{99 \mathrm{~m}} \mathrm{Tc}$ radionuclide is widely accessible in this field [48]. In a study, Taillefer et al. reported encouraging results in the detection of acute deep vein thrombosis (ADVT) by ${ }^{99 \mathrm{~m}} \mathrm{Tc}$-apcitide, a synthetic glycoprotein IIb/IIIa receptor-binding peptide. The authors reported a sensitivity of $86.4 \%$ in the detection of ADVT when early and delayed sets of images were analysed together [49]. ${ }^{99 \mathrm{~m}} \mathrm{Tc}$ sestamibi has been widely used in nuclear oncology, as it can be taken up by many tumor types, such as breast cancer, lung cancer, bone sarcoma, soft tissue sarcoma and lymphoma [50].

${ }^{99 m}$ Tc-labelled ciprofloxacin, which has a 4-fluoroquinolone backbone, was developed as a biologically active radiopharmaceutical to diagnose infection, based on its broad spectrum of antibacterial activity toward not only Gram-positive but also Gram-negative bacteria [51]. The antibacterial action of ciprofloxacin is mediated via strong binding to and inhibition of bacterial DNA gynase [52]. Currently used skeletal imaging agents are based on diphosphonate ligands, which depending on reaction conditions (e.g. $\mathrm{pH}$, molar ratio ligand/reductant, inert atmosphere, temperature, etc.) are mixtures of several oligomeric or polymeric ${ }^{99 \mathrm{~m}} \mathrm{Tc}$-diphosphonate complexes. Fosfomycin, the disodium salt of (-) cis 1, 2-epoxypropylphosphonic acid when labeled with Technetium-99m at $\mathrm{pH}=6.8$ in the presence of stannous chloride as reductant, was described as a renal imaging agent [53]. Nevertheless, at the same molar ratio ligand/reductant, but at $\mathrm{pH}$ $=2.5$ the radiopharmaceutical has shown bone uptake. Specific imaging of the spleen (i.e., with only minimal activity in the liver) is desirable in a number of clinical situations. These include the detection of accessory spleens, the evaluation of patients with suspected congenital asplenia or polysplenia, and the evaluation of patients with suspected splenic injury. The ideal agent for splenic imaging would have the high photon yield and low radiation dose of ${ }^{99 \mathrm{~m}} \mathrm{Tc}$-sulfur colloid and the high splenic specificity of damaged ${ }^{51} \mathrm{Cr}$-tagged red blood cells (RBCs) [54] or ${ }^{197} \mathrm{Hg}$ mercurihydroxypropane-labeled RBCs [55]. Theoretically, ${ }^{99 \mathrm{~m}} \mathrm{Tc}$ RBCs fulfill these requirements [56]. Recently, reproducible efficient methods of labeling RBCs with ${ }^{99 \mathrm{~m}} \mathrm{TcO}_{4}$ have become available [57], and the ${ }^{99 \mathrm{~m}} \mathrm{Tc}$ - RBCs may then be damaged to augment their uptake by the spleen [58]. ${ }^{99 \mathrm{~m}} \mathrm{Tc}$ has also very important application in labelling leukocytes [59].

Under certain conditions globular micelles are formed in aqueous solutions of phospholipids and cholesterol [60]. These structures have been referred to as liposomes [61]. Caride et al. described the use of liposomes as a delivery system for radiopharmaceutical localization. Liposomes [99m Tc-DTPA] were injected intravenously in mice and showed preferential uptake in the liver and spleen. There was a steady decline of activity in all organs, suggestive of destruction of liposomes with subsequent release of ${ }^{99 \mathrm{~m}} \mathrm{Tc}$-DTPA into the circulation. Alteration of uptake from liver to spleen, lung and bone marrow was achieved by prior loading of the circulation with nonradioactive liposomes. The authors also showed scintigraphically in dogs how ${ }^{99 m} \mathrm{Tc}-\mathrm{DTPA}$, when 
administered entrapped in liposomes, follows the pattern of distribution of liposomes [62]. The clinical evaluation of ${ }^{99 \mathrm{~m}} \mathrm{Tc}$-polyethyleneglycol liposomes showed that focal infection and inflammation could be adequately imaged with this agent [63].

Radio aerosols have certain inherent advantages over ${ }^{133} \mathrm{Xe}$ for measuring the distribution of ventilation. Radio aerosols are relatively inexpensive to produce. They can be delivered under tidal respiration, and even acutely ill patients can be adequately studied. When ${ }^{99 \mathrm{~m}} \mathrm{Tc}$ labelled aerosols are employed, images of high information density, comparable to perfusion images with ${ }^{99 \mathrm{~m}} \mathrm{Tc}$-macroaggregated albumin, can be obtained. Perhaps most importantly, aerosol inhalation images can be obtained in several projections, permitting close comparison with the distribution of perfusion [64]. Human serum albumin labeled with ${ }^{99 \mathrm{~m}} \mathrm{Tc}\left({ }^{99 \mathrm{~m}} \mathrm{Tc}-\mathrm{HAS}\right)$ is a valuable radiopharmaceutical widely employed for static and dynamic imaging of vascular spaces [65].

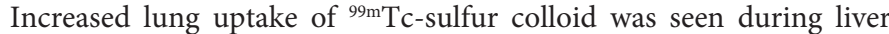
scanning in a patient with falciparum malaria. This finding was due to the enhanced activity of the phagocytic cells of the reticuloendothelial system in the liver, spleen and lung found in human and experimental malaria [66]. Sentinel lymph node (SLN) biopsy has emerged as a novel approach for identifying patients with melanoma and regional nodal micrometastasis who may benefit from full nodal basin resection. To identify the pattern of tumor lymphatic drainage and the SLN, lymphoscintigraphy has been performed using primarily ${ }^{99 \mathrm{~m}} \mathrm{Tc}$-sulfur colloid (SC). Bedrosian et al. have shown that ${ }^{99 \mathrm{~m} T c}$-human serum albumin (HAS) is also an effective radiotracer for identifying sentinel lymph nodes in melanoma [67].

Several reports described thiol compounds labeled with ${ }^{99 \mathrm{~m}} \mathrm{Tc}$ as potentially useful cholescintigraphic agents. Technetium-99m-labelled penicillamine $\left.{ }^{99 \mathrm{~m}} \mathrm{Tc}-\mathrm{Pen}\right)$ is an example of such type of agents [68]. The excretion of technetium into the bile has been uniquely linked to

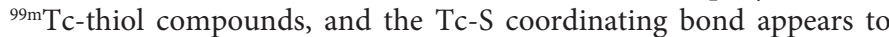
relate closely to the behavior of technetium in vivo. Technetium-99mglucoheptonate is an useful agent for brain scanning [69]. Since it was originally developed for renal imaging [70], the possibility of expanding the screening value of the brain scan at negligible cost was suggested. Immediately after brain scanning with a prospective technetium-99mglucoheptonate, the kidneys were imaged in 200 prospectively studied cases. Abnormalities were found in 22 cases (11\%); they included renal metastases, renal cysts and kidney displacement or obstruction by masses. In five instances, significant abnormalities previously unknown were found. The renal contours were usually better seen than on intravenous urograms or bone scans. Most kidney studies could be completed in less than two minutes, making renal imaging worthwhile as a low-cost high-yield routine addition to brain scanning [71].

Technetium labelled isonitrile compounds are used as potential clinical miocardial perfusion agent. ${ }^{99 \mathrm{~m} T \mathrm{~T}-\mathrm{MIBI}}$ is a type of complex which has rapid lung and liver clearance and slow myocardial washout. For this reason this radiopharmaceutical is used for imaging of the myocardium [72]. Esophagitis is a common complication of gastroesophageal reflux disease (GERD). Unfortunately, an accurate diagnosis of esophagitis usually requires invasive endoscopy. Kao et al. studied and evaluated that noninvasive ${ }^{99 \mathrm{~m}} \mathrm{Tc}-\mathrm{MIBI}$ chest SPECT has excellent sensitivity and good accuracy as a screen for esophagitis [73]. In a recent study, Wakasugi et al. shown that ${ }^{99 \mathrm{~m}} \mathrm{Tc}-\mathrm{MIBI}$ scans have better sensitivity for detecting bone metastases and provide more specific complementary findings than conventional bone scans. ${ }^{99 \mathrm{~m}} \mathrm{Tc}$ MIBI accumulation attributed to bone marrow metastases may occur at an early stage, before the bone remodeling process in the surrounding bone can be detected on conventional bone scans [74]. While studying the correlation of ${ }^{99 \mathrm{~m}} \mathrm{Tc}$-mebrofenin handling with liver morphology, function and copper accumulation in Long-Evans Agouti rats, Malhi et al. suggested that ${ }^{99 \mathrm{~m}} \mathrm{Tc}$-mebrofenin scintigraphy can be useful for noninvasively monitoring disease progression and therapeutic response in Wilson's disease [75].

\section{Radioisotopes of ruthenium}

The radionuclides of ruthenium have been investigated as potentially useful in nuclear medicine applications. The radioisotope ${ }^{97} \mathrm{Ru}$ is an important label for both diagnostic imaging and therapeutic purpose because of its excellent physical and chemical properties $\left[\mathrm{T}_{1 / 2}=2.9 \mathrm{~d}, 100 \% \mathrm{EC}, \mathrm{E}_{\gamma}=215.7 \mathrm{keV}(85.8 \%)\right.$ and $324.5 \mathrm{keV}(10.2 \%)$, no beta emissions to contribute to the radiation dosage and a few different valence state] [76]. The $\left[{ }^{97} \mathrm{Ru}\right]$ PIPIDA [N, $\alpha$-(p-isopropyl-acetanilide) iminoacetic acid] complex has got tremendous importance as a potential hepatobiliary diagnostic agent. The above complex of ruthenium is able to provide better diagnostic information of hepatobiliary conditions in comparison to ${ }^{131} \mathrm{I}^{-}$or ${ }^{99 \mathrm{~m}} \mathrm{Tc}$-labelled radiopharmaceuticals [77]. In fact ${ }^{97} \mathrm{RuPIPIDA}$ can be successfully used for prolonged examination of liver and gallbladder disorders instead of ${ }^{99}$ TcPIPIDA. The application of $\left[{ }^{97} \mathrm{Ru}\right]$ PIPIDA would reduce the radiation dose to two fold to the patient. The ${ }^{97} \mathrm{Ru}$-labelled monoclonal antibodies are produced for radioimminotherapy [76,78]. Bleomycin (BLM) has undergone extensive investigations both as a cancer chemotherapeutic agent and as a carrier for radionuclides for imaging. ${ }^{97} \mathrm{Ru}$ is used for the above mentioned purposes. In the diagnosis of tumours ${ }^{97} \mathrm{Ru}$-transferrin can also be used for the same purpose [79]. This complex can act as a positive substitute of ${ }^{67} \mathrm{Ga}$-citrate [80]. The ${ }^{97} \mathrm{Ru}$-DISIDA is a suitable agent for liver imaging [81]. $\left[{ }^{97} \mathrm{Ru}\right]$ DTPA is employed as a cerebrospinal-fluid imaging agent [82].

The ruthenium-red complex incorporating the radioisotope ${ }^{103} \mathrm{Ru}$ can act as a tumor scanning agent. Its accumulation seems to be related to its specific binding to mucopolysaccharides. In addition, this radio compound shows potential value in the study of other pathological states involving the metabolism of mucopolysaccharides and glycoproteins. ${ }^{103} \mathrm{Ru}$ is also used in the scintigraphy of patients with various types of malignant tumours. Head and neck tumours were identified as strongly positive in $>75 \%$ of the cases. Two cases with inflammatory lesions showed positive scans with ${ }^{103} \mathrm{Ru}$. The ruthenium radionuclides are therefore probably not suitable for differentiating carcinoma from inflammatory states [83]. Metallocenes labeled with ${ }^{103} \mathrm{Ru}$ have important applications in nuclear medicine diagnosis. While ${ }^{103} \mathrm{RuCl}_{3}$ was evenly distributed in the body of an experimental animal, the metallocene derivatives were concentrated in the liver, lungs and spleen after i.v. injection. Metallocene labeled with ${ }^{103} \mathrm{Ru}$ showed an extremely high kidney-to-muscle ratio of accumulation (up to 1000) [84]. ${ }^{99 \mathrm{~m}} \mathrm{Tc}$-labelled renal agents tested for comparison showed lower ratios. The radioisotope ${ }^{106} \mathrm{Ru}$ forms a chelate with 2-3 dimercaptopropane sulfonic acid (DMPS) which has pronounced affinity for kidney [85].

\section{Radioisotopes of rhodium}

Radionuclides which emit auger and Coster-Kronig electrons following the electron capture mode of decay have been recently studied for their therapeutic potential [86]. This is due, primarily, to the discovery of the radiotoxicity resulting from the deposition of their electron energy in an extremely small volume within the DNA of the cell nucleus [87]. ${ }^{101 \mathrm{~m}} \mathrm{Rh}$ is one such radionuclide that has been considered as a potential candidate for targeted radiotherapeutic use, 
due to its nuclear decay and chemical properties. It decays with a half life of 4.34 days by electron capture $(92.8 \%)$ to stable ${ }^{101} \mathrm{Ru}$ and by isomeric transition $(7.2 \%)$ to ${ }^{101} \mathrm{Rh}\left(\mathrm{T}_{1 / 2}=3.2 \mathrm{yr}\right)$. Its major $\gamma$-ray emissions are $308.8 \mathrm{keV}$ (87.2\%) and $544 \mathrm{keV}$ (4\%). The $308.8 \mathrm{keV}$ $\gamma$-ray is useful for in vivo monitoring with a scintillation camera. Its decay has no $\beta$-particle emissions, only Auger and Coster-Cronig electrons of energies ranging from $0.396-21.170 \mathrm{keV}$ are emitted; the average depth of penetration of these being $0.01-10 \mu \mathrm{m}$ in unit density tissue $[88,89]$

\section{Radioisotopes of palladium}

Interstitial implantation of radiation-emitting materials has been long recognized as effective method for tumor therapy. The advantage of interstitial implants is an opportunity to concentrate the radiation at the tumor site while minimizing radiation exposure to normal tissue. The carrier free ${ }^{103} \mathrm{Pd}$ radioisotope has more favourable physical properties, including its low energy, rapid dose fall-off, short halflife and total cumulative dose delivery and hence it is a promising radioisotope for localized tumour treatment [90]. ${ }^{103} \mathrm{Pd}$ brachytherapy sources are being used for interstitial brachytherapy implants in various tumour sites and particularly for prostatic carcinomas [91]. One of the key techniques for the preparation of ${ }^{103} \mathrm{Pd}$ seed is coating onto carrier. Recently, Zhang et al. described a method for ${ }^{103} \mathrm{Pd}$ "molecular plating" onto the surface of a silver rod [92].

\section{Radioisotopes of silver}

The use of antibodies labeled with various radionuclides to deliver therapeutic doses of radiation for human cancer treatment has now been shown to give clinically significant effects in a number of studies [93]. Such radioimminotherapy (RAIT) is dependent on several contributing factors including the radiosensitivity of the target tumor, the characteristic of the chosen antibody and, of course, the nature of the nuclide employed [94]. The carrier-free ${ }^{111} \mathrm{Ag}$ isotope has been suggested to be more suitable for RAIT than the commonly used ${ }^{131} \mathrm{I}$, on the basis of its good $\beta$-emission properties, appropriate half-life of 7.5 days and much more favourable $\gamma$-ray component $(342 \mathrm{keV}, 6 \%$ for ${ }^{111} \mathrm{Ag}$ compared with $363 \mathrm{keV}, 82 \%$ for ${ }^{131} \mathrm{I}$ ) [95].

\section{Radioisotopes of cadmium}

As a source of $\mathrm{x}$-radiation the carrier-free ${ }^{109} \mathrm{Cd}$ has much wider applications. Two main lines with energy $\mathrm{E}_{\gamma}=22.1 \mathrm{keV}$ and $\mathrm{E}_{\gamma}=24.04$ $\mathrm{keV}$ characterize the energy of this radiation [96]. The radioisotopes of cadmium in no carrier added form have excellent applications in the metallobiochemical studies at sub cellular and molecular levels with the identification of the cadmium binding components. The long term metabolic studies are carried out with ${ }^{109} \mathrm{Cd}$ having sufficiently long half life. On the contrary due to short half life of ${ }^{107} \mathrm{Cd}$ it is used for short term experiment [97]. This ${ }^{107} \mathrm{Cd}$ radioisotope can also be potentially used to label specific cadmium binding proteins from different origins which should be subsequently used for in vitro studies and structural investigations. This particular ${ }^{107} \mathrm{Cd}$ radioisotope would also be employed to study the metabolic patterns of different isotopically labeled $\mathrm{Cd}^{2+}$ ions such as ${ }^{109} \mathrm{Cd},{ }^{115} \mathrm{Cd}$ and ${ }^{107} \mathrm{Cd}$ simultaneously administered by various routes of energy/ingestion, injection and inhalation/ detecting the cadmium radioisotopes in the cellular components by high resolution computer coupled $\gamma$-ray spectrometry [98]. Identification of micro amounts of cadmium components in kidney, liver, intestine and pancreas and determination of the accumulation pattern of cadmium in different organs will be possible by the administration of ${ }^{109} \mathrm{Cd}$ radiotracer in combination with neutron activation analysis [97].

\section{Conclusion}

Although apart from Nuclear Medicine, different imaging modalities such as Computerised Tomography using $\mathrm{X}$-rays (CT scanning), Magnetic Resonance Imaging (MRI), Ultra Sound Scanning are also used, the role of Nuclear Medicine has been proven to be vital in many areas. The predictions that Nuclear Medicine Imaging will become obsolete when MRI was introduced did not come true and in fact, the current trends are to use these modalities in conjunction with each other to obtain the maximum information. The diagnostic imaging using radiopharmaceuticals has come a long way and nearly all the organs of interest can be imaged currently. The concepts of tomographic images leading to SPECT and latter high resolution SPECT have resulted in excellent pictures with ${ }^{99 \mathrm{~m}} \mathrm{Tc}$ radiopharmaceutical agents. The focus in radiopharmaceutical chemistry has hence been to develop better radiopharmaceutical agents for imaging the vital organs and systems using ${ }^{99 \mathrm{~m}} \mathrm{Tc}$ based radiopharmaceuticals and this aim has been achieved to a large extent. In the U. S. among the 30 million people who are hospitalised each year one in three is treated with nuclear medicine. There more than 10 million nuclear medicine procedures and more than 100 million tests are done each year with nuclear medicine. A significant number of such procedures are also performed in the rest of the world [99]. The use of radiotracers is not limited to in vivo studies but has also opened an era of "Test Tube Nuclear Medicine". Radiolabelling of proteins and especially antibodies as tracers has introduced biotechnologies of unimaginable sensitivities of detection of molecules. The introduction of radioimmunoassay techniques in the early 1960's by Berson and Yalow from United States and Ekin's from U. K. have revolutionised diagnostic medicine [100].

Though the carrier free radioisotopes are preferred to the isotopic radioactivity especially for in vivo applications however the production of radiochemically pure carrier free isotopes is still a challenging and fascinating problem to the nuclear scientists. The production of carrier free nuclides by charged particle activation with the help of modern high energy particle accelerator and development of suitable radiochemical methodologies for isolation and purification of these product nuclides from the bulk target matrix will greatly meet the increasing demand for carrier free radioisotopes in medical sciences and will also enhance the scope of nuclear medicine. In spite of the enormous applications of the radiopharmaceuticals in nuclear medicine, design, development and marketing of any pharmaceutical is expensive. Preparations of radiopharmaceuticals also introduce additional variables and risk factor related to the choice of radionuclide and associated radiation.

\section{References}

1. Friedlander G, Kennedy JW, Macias ES, Miller JM (1981) "Nuclear and Radiochemistry" John Wiley \& Sons New York

2. Hosain Fazle (1996) Radiopharmaceuticals: Therapeutic Applications.100 years of X-Rays and Radioactivity Bhabha Atomic Research Centre, Mumbai, India, p. 447-461.

3. Zuckerman JD, Sledge CB, Shortkroff S, Venkatesan P (1987) Treatment of rheumatoid arthritis using radiopharmaceuticals. Nucl Med Biol 14: 211- 218.

4. Davis MA, Chinol M (1989) Radiopharmaceuticals for radiation synovectomy Evaluation of two yttrium-90 particulate agents. J Nucl Med 30: 1047- 1055.

5. Pandey U, Mukherjee A, Chaudhary PR, Pillai MRA, Venkatesh M (2001) Preparation and studies with ${ }^{90} \mathrm{Y}$-labelled particles for use in radiation synvectomy. Appl Radiat Isot 55: 471- 475.

6. Hsieh BT, Ting G, Hsieh HT, Shen LH (1993) Preparation of carrier free ${ }^{90} \mathrm{Y}$ fo medical applications by solvent extraction chromatography. Appl Radiat Isot 44: 1473- 1480.

7. Mantravadi RVP, Spigos DG, Tan WS, Felix EL, (1982) Intraarterial yttrium-90 in the treatment of hepatic malignancy. Radiology 142: 783- 787. 
Citation: Mukhopadhyay B, Mukhopadhyay K (2011) Applications of the Carrier Free Radioisotopes of Second Transition Series Elements in the Field of Nuclear Medicine. J Nucl Med Radiat Ther 2:115. doi:10.4172/2155-9619.1000115

Page 7 of 9

8. Pandey U, Mukherjee A, Sarma HD, Das T, Pillai MRA, et al. (2002) Evaluation of ${ }^{90} \mathrm{Y}$-DTPA and ${ }^{90} \mathrm{Y}$-DOTA for potential application in intra-vascula radionuclide therapy. Appl Radiat Isot 57: 313-318.

9. Lenarczyk M, Goddu SM, Dandamudi VR, Howell RW (2001) Biologic dosimetry of bone marrow: Induction of micronuclei in reticulocytes after exposure to ${ }^{32} \mathrm{P}$ and ${ }^{90}$ Y. J Nucl Med 42: 162-169.

10. Wagner HN, Wiseman GA, Marcus CS et al. (2002) Administration guidelines for Radioimmunotherapy for non-Hodgkin's lymphoma with ${ }^{90} \mathrm{Y}$-labeled antiCD20 monoclonal antibody. J Nucl Med 43: 267- 272.

11. Beyer GJ, Bergmann R, Kampf G, Mading P, Rosch F et al, (1992): Simultaneous study of the biodistribution of radio-yttrium complexed with EDTMP and citrate ligands in tumour-bearing rats. Nucl Med Biol 19: 201- 205.

12. Rosch F, Qaim SM, Stocklin G (1993) Production of the positron emitting radioisotope ${ }^{86} Y$ for nuclear medical application. Appl Radiat Isot 44: 677- 681.

13. Link JM, Krohn KA, Eary JF, Kishore R, Lewellen TK, et al, (1986) ${ }^{89} \mathrm{Zr}$ for antibody labelling and positron tomography. J Labelled Compd Radiopharm 23: 1296-1297.

14. Dejesus OT and Nickless RJ (1990) Production and purification of ${ }^{89} \mathrm{Zr}$, a potential PET antibody label. Appl. Radiat. Isot. 41: 789-790.

15. Goerner W, Noll B, Spies H, Thieme K (1988) Determination of technetium in ${ }^{99} \mathrm{Mo} /{ }^{99 m} T \mathrm{~T}-$ generators. J Radioanal Nucl Chem 122: 291-298.

16. Chervu LR, Lee HB, Goyal Q, Bloufox MD (1977) Use of 99mTc-Cu-DTPA complex as a renal function agents. J Nucl Med 18: 62-66.

17. Marchi A, Uccelli L, Bonardi M, Gallorini M, Groppi F, et al. (1995) Technetium complexes with ligands of pharmacological interest. J Radioanal Nucl Chem Art195: 237- 242

18. Neirinckx RD, Canning LR, Piper IM, Nowotnik DP, Picket RD, et al.(1987) A new radiopharmaceutical for SPECT imaging of regional cerebral blood perfusion. J Nucl Med 28: 191- 192.

19. Vallabhajosula S, Zimmerman RE, Picard M, Stritzke P, Mena I, (1989) Technetium-99m-ECD a new brain imaging agent, In vivo kinetics and biodistribution studies in normal human subjects J Nucl Med 30: 599- 604

20. Kothari K, Banerjee S, Sharma HD, Pillai MRA. (2000) Synthesis and radiolabeling of cysteine-oximes and pharmacological behaviour of their ${ }^{99 \mathrm{~m} T c}$ complexes. Appl Radiat Isot 52: 69- 76.

21. Pankaj P, Sen IB, Gupta A, Bembey S, Baruah B, et al. (2001) Localization of an infected cyst in adult polysistic kidney by Tc-99m HMPAO labeled leucocyte scan. Ind J Nucl Med 16: 138-140.

22. Ding HJ, Shiau YC, Tsai SC, Wang JJ, Ho ST, (2002) Uptake of 99mTc tetrofosmin in lymphoma cell lines: a comparative study with ${ }^{99 m} \mathrm{Tc}$ sestamibi. Appl Radiat Isot 56: 853-856.

23. Kao CH, Hsieh JF, Tsai SC, Ho YJ, Changlai SP, et al. (2001) Paclitaxel-based chemotherapy for non small cell lung cancer: Predicting the response with ${ }^{99 m}$ Tc-tetrofosmin chest imaging. J Nucl Med 42: 17- 20.

24. Holman BL (1976) Radionuclide Methods in evaluation of Myocardial Ischemia and infarction. Circulation 53: 112- 118.

25. Umezawa H (1965) Bleomycin and other antitumour antibiotics of high molecular weight. Antimicrob Agents Chemother 5: 1079-1085.

26. Bonadonna G, Delena M, Monfardini S, Bartoli C, Bajetta E et al. (1972) Clinical trial with bleomycin in lymphomas and in solid tumours. Eur $\mathrm{J}$ Cancer 8: 205215

27. Benjamin PP (1969) A rapid and efficient method of preparing ${ }^{99 m} \mathrm{Tc}$-human serum albumin, Its clinical applications. Int J Appl Radiat Isot 20: 187- 194.

28. Lin MS, Weber PM, Winchel HS et al. (1972) Renal imaging in humans with the technetium labelled polypeptide cascidin J Nucl Med 13: 517- 521.

29. Lin MS, Goodwin DA, Kruse SL (1974) Bleomycin as a ${ }^{99 \mathrm{~m} T c}$ carrier in tumor visualisation. J Nucl Med 15: 338- 342.

30. Lin TH, Khentigan AA, Winchel AS (1974) ${ }^{99 m}$ Tc-chelate for organoradiomercurial renal agents. J Nucl Med 15: 34- 35

31. Hauser W, Atkins HL, Welson KG et al. (1970) Technetium-99m DTPA: A new rsdiopharmaceutical for brain and kidney scanning. Radiology 94: 679- 684.

32. Subramanian G, Mcafee JG, Mchter A et al. (1973) ${ }^{99 \mathrm{~m} T c-s t a n n o u s ~ p h y l a t e: ~ A ~}$ new in vivo colloid for imaging the reticuloendothelial system. J Nucl Med 14 459- 463.

33. Bekerman C, Gottschalk A (1971) Diagnostic significance of the relative uptake of liver compared to spleen in ${ }^{99 m} \mathrm{Tc}$-sulfur colloid scintigraphy. J Nucl Med 12 237- 240 .

34. Baldas J, Bonnyman J (1985) Effect of the Tc-nitrido group on the behaviour of 99mTC-radiopharmaceuticals. Int J Appl Radiat Isot 36: 919- 923

35. Zhang J, Wang X (2001) Preparation of ${ }^{99 \mathrm{~m}} \mathrm{TcN}(\mathrm{CBDTC})_{2}$ and its biodistribution in mice. Appl Radiat Isot 55: 453- 456

36. Zhang C, Wang Y, Tian H, Yin D (2002) Preparation of ${ }^{103} \mathrm{Pd}$ seed-molecular plating of ${ }^{103} \mathrm{Pd}$ onto silver rod. Appl Radiat Isot 57: 309- 311.

37. Wistow BW, Subramanium G, Van Heertum R (1977) An evaluation of 99m Tc-labelled hepatobilliary agents. J Nucl Med 18: 455- 461

38. Schaffer EA, Mcormond P, Dugan H (1980) Quantitative cholescintigraphy: assesment of gallblader filling and empty and duodenogastric reflux. Gastroenterology 79: 899- 906

39. Krishnamurthy GT, Bobba VR, Kingston E (1981) Radionuclide ejection fraction: a technique for quantitative analysis of motor function of the human gallbladder. Gastroenterology 80: 482- 490.

40. Gambhir SS, Hawkins RA, Huang SC, Hall TR, Busuttil RW et al. (1989) Trace kinetic modelling approaches for the quantification of hepatobillary function with technetium-99m DISIDA and scintigraphy. J Nuc Med 30:1507-1518.

41. Mushtaq A, Pervez SH, Haider I, Mansur MS, Jehangir M (2000) A freez dried kit for ${ }^{99 m} \mathrm{Tc}(\mathrm{V})$ dimercaptosuccinic acid. J Radioanal Nucl Chem 243: 827- 829.

42. Wang $X(2000)$ Synthesis and biodistribution of the 99m TcN-DMSA complex as a potential bone imaging agent. J Radioanal Nucl Chem 243: 827-829.

43. Rosch F, Novgoredov AF, Qaim SM (1994) Thermochromatographic separation of ${ }^{94 \mathrm{~m} T c}$ from enriched molybdenum targets and its large scale production for nuclear medical application. Radiochim Acta 64: 113- 120

44. Rösch F, Qaim SM (1993) Nuclear data relevant to the production of the positron emitting technetium isotope ${ }^{94 \mathrm{~m}} \mathrm{Tc}$ via the ${ }^{94} \mathrm{Mo}(p, n)$ reaction. Radiochim Acta 62: 115- 121.

45. Groshar D, Slobodin G, Zuckerman E (2002) Quantitation of liver and spleen uptake of ${ }^{99 \mathrm{~m} T c-p h y t a t e}$ colloid using SPECT: Detection of liver cirrhosis. J Nuc Med 43: 312- 317

46. Hwang JJ, Liao MH, Yen TC, Wey SP, Lin KJ, et al. (2002) Biodistribution study of $\left.{ }^{99 \mathrm{~m}} \mathrm{Tc}\right]$ TRODAT-1 alone or combined with other dopaminergic drugs in mice with macroautoradiography. Appl Radiat Isot 57: 35- 42.

47. Murugesan S, Shetty SJ, Srivastava TS, Noronha OPD, Samuel AM (2001) A technetium-99m-labelled cyclam acid porphyrins (CAP) for tumour imaging. Appl Radiat Isot 55: 641- 646

48. Pervez S, Mushtaq A, Arif M (2001) Technetium-99m direct radiolabeling of Lanreotide: a Somatostatin analog. Appl Radiat Isot 55: 647- 651

49. Taillefer R, Therasse E, Turpin S, Lambert R, Robillard P et al (1999) Comparison of early and delayed scintigraphy with ${ }^{99 m} \mathrm{Tc}$-apcitide and correlation with contrast-enhanced venography in detection of acute deep vein thrombosis. J Nucl Med 40: 2029- 2035.

50. Sasaki M, Kuwabara Y, Ichiya Y, Yoshida T, Nakagaoa M, et al. (1999) Prediction of the chemosensitivity of lung cancer by $99 \mathrm{mTc}$-hexakis-2 methoxyisobutyl isonitrile SPECT. J Nucl Med 40: 1778- 1783.

51. Goodman GA (1991) The Pharmacological Basis of Therapeutics, $2^{\text {nd }}$ Edition Pergamon Press, Oxford, pp.1057-1064.

52. Oh SJ, Ryu JS, Shin JW, Yoon EJ, Ha HJ et al. (2002) Synthesis of ${ }^{99 m} \mathrm{Tc}$ ciprofloxacin by different methods and its biodistribution. Appl Radiat Isot 57 193- 200.

53. Lima KP (1985) Renalgammagraphy with ${ }^{99 m}$ Tc-phosphomycin. Eur J Nucl Med 10: $134-138$

54. Wagner HN, McAfee JG, Winkelman JW (1982) Splenic disease diagnosis by radioisotope scanning. Arch Intern Med 109: 673-684.

55. Korst DR, Nixon JC, Boblitt DE, Quirk J (1965) Studies of selective splenic sequestration of erythrocytes labeled with radioactive mercurihydroxypropane (MHP). J Lab Clin Med 66: 788- 803. 
Citation: Mukhopadhyay B, Mukhopadhyay K (2011) Applications of the Carrier Free Radioisotopes of Second Transition Series Elements in the Field of Nuclear Medicine. J Nucl Med Radiat Ther 2:115. doi:10.4172/2155-9619.1000115

Page 8 of 9

56. Anghileri LJ, Lee JI, Miller ES (1970) The ${ }^{99 \mathrm{~m} T c}$ labelling of erythrocytes. J Nucl Med 11: 530-533.

57. Gutkowski RF, Dworkin JH (1976) Kit-produced ${ }^{99 m}$ Tc-labelled red cells for spleen imaging. J Nucl Med 15: 1187-1191.

58. Wagner HN, Razzak MA, Gaertner RA, Caine WP Jr, Feagin OT (1962) Removal of erythrocytes from the circulation. Arch Intern Med 110: 90- 97.

59. Uchida T and Vincent PC (1976) In vitro studies of leukocytes labelling with technetium-99m. J Nucl Med 17: 730- 736.

60. Paphadjopoulos D, Miller N (1967) Phospholipid model membranes. I. Structural characteristics of hydrated liquid crystals. Biochim Biophys Acta 135: 624- 638

61. Sessa G, Weissman G (1968) Phospholipid spherules (liposomes) as a model for biological membranes. J Lipid Res 9: 310-318.

62. Caride VJ, Tayler W, Cramer JA and Gottschalk A (1976) Evaluation of liposome-entrapped radioactive tracers as scanning agents. Part 1: organ distribution of liposome (99mTc-DTPA) in mice. J Nucl Med 17: 1067- 1072.

63. Dams ET, Oyen WJ, Boerman OC, Storm G, Laveman P, et al. (2000) 99mTcPEG liposomes for the scintigraphic detection of infection and inflammation: clinical evaluation. J Nucl Med 41, 622- 630.

64. Wasnich RD (1976) A high frequency ultrasonic nebulizer system for radioaerosol delivery. J Nucl Med 17: 707- 710.

65. Porter WC, Dworkin HJ, Gutkowski RF (1976) The effect of carrier technetium in the preparation of ${ }^{99 m}$ Tc-human serum albumin. J Nucl Med 17: 704-706.

66. Ziessman HA (1976) Lung uptake of 99mTc-sulfur colloid in falciparum malaria: J Nucl Med 17: 794-796.

67. Bedrosian I, Scheff AM, Mick R, Callans LS, Bucky LP, et al. 99mTc-human serum albumin: an effective radiotracer for identifying sentinel lymph nodes in melanoma. J Nucl Med 40: 1143-1148.

68. Tubis M, Krishnamurthy GT, Endow JS, Blahd WH (1972) 99mTc-penicillamine a new cholescintigraphic agent. J Nucl Med 13: 652-654.

69. Waxman AD, Tanacescu D, Siemsen JK, Wolfstein RS (1975) Technetium$99 \mathrm{~m}$ glucoheptonate as a brain scanning agent: A critical comparison with pertechnetate. J Nucl Med 16: 580-581.

70. Boyd RE, Robson J, Hunt FC, Sorby PJ, Murray IP, et al. (1973) 99mTcgluconate complexes for renal scintigraphy. Br J Radiol 46: 604-612.

71. Kahn PC, Dewanjee MK and Brown SS (1976) Routine renal imaging after 99mTc-glucoheptonate brain scans. J Nucl Med 17: 786-787.

72. Takahasi M (1997) New frontiers of diagnostic radiology. Asia-pacific symposium on radiochemistry-Kumamoto, Japan, 6-9 October 13-14.

73. Kao CH, Hsieh JF, Tsai SC, Ho YJ, Sun SS (2000) Detection of esophagitis by 99mTc-methoxyisobutylisonitrile chest SPECT. J Nucl Med 41: 1969-1972.

74. Wakasugi S, Noguti A, Katuda T, Hashizume T, Hasegawa Y (2002) Potential of $(99 \mathrm{~m}) \mathrm{Tc}-\mathrm{MIBI}$ for detecting bone marrow metastases. J Nucl Med 43: 596602.

75. Malhi H, Bhargava KK, Afriyie MO, Volenberg I, Schilski ML, et al. (2002) $99 \mathrm{mTc}$-mebrofenin scintigraphy for evaluating liver disease in a rat model of Wilson's disease. J Nucl Med 43: 246-252.

76. Srivastava SC, Richerds P, Meinken, GE, Larson SM, Grunbaum Z (1981) Radiopharmaceuticals-Structure-Activity Relationships, Ed RP Spencer 207.

77. Schachner ER, Gil MC, Atkins HL, Som P, Srivastava SC, et al. (1981) Ruthenium- 97 hepatobiliary agents for delayed studies of the biliary tract. $J$ Nucl Med 22: 352-357.

78. De Nardo SJ, Jungerman JA, Denardo GL, Lagnus-Solar MC, Cole WC, et al (1985) Int symp on the developing role of short lived radionuclides in nuclear medical practice. Con- 820523 (DE82008258), Eds P Paras and JW Thiessen 401

79. Shao HS, Meinken GE, Srivastava SC, Slosman D, Sacker DF, et al. (1986) In vitro and in vivo characterization of ruthenium bleomycin compared to cobalt and copper bleomycin. J Nucl Med 27: 1044-1047.

80. Som P, Oster JH, Matsui K, Guglielmi G, Persson BRR, et al. (1983) ${ }^{97} \mathrm{Ru}-$ transferrin uptake in tumour and abscess. Eur J Nucl Med 8: 491-496.
81. Zanzi I, Srivastava SC, Meinken GE, Robeson W, Mausner LF, et al. (1986) A new cholescintigraphic agent ${ }^{97}$ Ru-DISIDA. J Nucl Med 27: 1072-1075.

82. Oster ZH, Som P, Gil MC, Fairchild RG, Goldman AG, et al. (1981) Ruthenium-97 DTPA: a new radiopharmaceutical for cisternography. J Nucl Med 22: 269-273.

83. Gessner M, Music S, Bararovic B and Vlatkovic M: Investigation on the preparation of ${ }^{97} \mathrm{Ru}$. Int J Appl Radiat Isot 30: 578-578.

84. Wenzel M, Nipper E, Klose W (1977) Biochemistry of metalocenes.1.Distribution of $59 \mathrm{Fe}$ or $103 \mathrm{Ru}$-labelled metalocene carboxylic acid in mice. J Nucl Med 18 367-372.

85. Comar D, Crouzel C (1976) Ruthenium-97 preparation with a compact cyclotron. Radiochem Radioanal Lett 27: 307-312.

86. Volkert WA, Goeckeler WF, Ehrhardt GJ, Ketring AR (1991) Therapeutic radionuclides: production and decay property consideration. J Nucl Med 32 : 174-184.

87. Hofer KG and Hughes WL (1971) Radiotoxicity of intranuclear Tritium, ${ }^{125}$ I and ${ }^{131}$. Radiat Res 47: 94-109.

88. Cole A (1969) Absorption of $20 \mathrm{eV}$ to $50,000 \mathrm{eV}$ electron beam in air and plastic. Radiat Res 38: 7-33.

89. Ramli M, Sharma HL (1997) Radiochemical separation of ${ }^{101 \mathrm{~m} R \mathrm{R}}$ via ${ }^{101} \mathrm{Pd}$ from a rhodium target. Appl Radiat Isot 48: 327-331.

90. Chunfu Z, Yongxian W, Yongping Z, Xiuli Z (2001) Cyclotron production of no-carrier-added palladium-103 by bombardment of rhodium-103 target. App Radiat Isot 55: 441-445.

91. Porrazzo MS, Hilaris BS, Moorthy CR (1992) Permanent interstitial implantation using palladium-103: the New York medical college preliminary experience. Int J Radiat Oncol Biol Phys 23: 1033-1036.

92. Zhang J, Wang X, Li CY (2002) Synthesis and biodistribution of a new ${ }^{99 m} \mathrm{TC}$ nitrido complex as a potential myocardial and cerebral imaging agent. Appl Radiat Isot 56: 857-867.

93. Brady LW, Wood DV, Markoe AM, Dadparvar S, Karlsson U (1990) Treatment of malignant gliomas with ${ }^{125}$-labelled antibody against epidermal growth factor receptor. Antibody Immunoconj Radiopharm 3: 169-173.

94. Mansur MS, Mushtaq A, Muhammad A (1995) Separation of ${ }^{111} \mathrm{Ag}$ from neutron irradiated natural palladium. Radiochim Acta 68: 161-162.

95. Browne E, Firestone RB (1986) Table of radioactive isotopes (Ed VS Shirley) John Wiley \& Sons, New York.

96. Gureev ES, Islamov TI, Usachenko VS and Gilbert EN (1979) Radiochemical scheme for obtaining carrier free cadmium-109. Radiokhimiya 21: 422-426.

97. Goetz I, Sabbioni E, Marafante E, Birattari C, Bonardi M (1980) Cyclotron production of ${ }^{107,109} \mathrm{Cd}$ for use in metallobiochemistry or heavy metal pollution. Radiochem Radioanal Lett 45: 51-60.

98. Guzzi G, Pietra R, Sabbioni E (1976) Determination of 25 elements in biological standard reference materials by neutron activation analysis. J Radioanal Chem 34: $35-57$.

99. Seaborg GT (1996) FOREWORD 100 years of X-Rays and Radioactivity Bhabha Atomic Research Centre, Mumbai, India.

100.Samuel AM (1996) 100 years of X-Rays and Radioactivity. Bhabha Atomic Research Centre, Mumbai, India 437.

101.Zweit J, Downey S, Sharma HI (1991) Production of no-carrier-added zirconium-89 for positron emission tomography. Appl Radiat Isot 42: 199-201.

102. Lahiri S, Mukhopadhyay B, Das NR (1997) Simultaneous production of ${ }^{89} \mathrm{Zr}$ and ${ }^{90,91 \mathrm{~m}, 92 \mathrm{~m}} \mathrm{Nb}$ in a-particle activated yttrium and their subsequent separation by HDEHP. Appl Radiat Isot 48: 883-886.

103. Chuang JT, Lo JG (1995) The solvent extraction of carrier free ${ }^{90} \mathrm{Y}$ from ${ }^{90} \mathrm{~S}$ with crown ethers. J Radioanal Nucl Chem 189: 307-317.

104. Muddukrishna SN, Narasimnan DVS, Desai CN (1990) A novel technique for the separation of ${ }^{99 \mathrm{~m} T c}$ from ${ }^{99} \mathrm{Mo}$. J Radioanal Nucl Chem 140: 153-157.

105. Lahiri S, Mukhopadhyay B, Das NR (1997) LLX separation of carrier-free

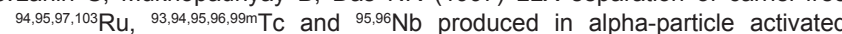
molybdenum by TOA. J Radioanal Nucl Chem 221: 167-171. 
Citation: Mukhopadhyay B, Mukhopadhyay K (2011) Applications of the Carrier Free Radioisotopes of Second Transition Series Elements in the Field of Nuclear Medicine. J Nucl Med Radiat Ther 2:115. doi:10.4172/2155-9619.1000115

106. Lagunas-Solar MC, Kiefer PM, Carvacho OF, Lagunas CA and Cha YP (1991)

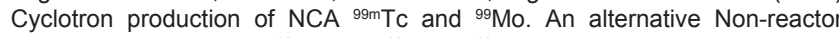
supply source of instant ${ }^{99 \mathrm{~m}} \mathrm{Tc}$ and ${ }^{99} \mathrm{Mo} \rightarrow{ }^{99 \mathrm{~m} T c}$ generators. Appl Radiat Isot 42: 643-657.

107.Lahiri S, Mukhopadhyay B (1997) Liquid-liquid Extraction of carrier-free radioisotopes produced in $\alpha$-particle activated molybdenum target by HDEHP and TBP. Appl Radiat Isot 48: 925-929.

108. Bonardi M, Gallorini M, Birattari C, Groppy F, Magon L, et al. (1995) Irradiation methods for production of high specific activity radionuclides in no carrier added form. J Radioanal Nucl Chem 195: 227-236.

109. Lahiri S, Mukhopadhyay B, Nandy M, Das NR (2005) Sequential separation of carrier-free $101,105,106 \mathrm{Rh}, 103,104,105,106,110,112 \mathrm{Ag}$ and $104,105,107,109,111 \mathrm{Cd}$ produced in alpha-particle activated palladium by HDEHP. J Radioanal Nucl Chem 224: 155-158.
110. Hermanne A, Sonck M, Takacs S, Tarkanyi F, Shubin Y (2001) Study on alternative production of ${ }^{103} \mathrm{Pd}$ and characterization of contaminants in deuteron irradiation of ${ }^{103} \mathrm{Rh}$ up to $21 \mathrm{MeV}$. Nucl Insrt Meth.

111. Fassbender M, Nortier FM, Schroeder IW, Van Der Walt TN (1999) The production of ${ }^{103} \mathrm{Pd}$ via the ${ }^{\mathrm{nat}} \mathrm{Ag}(\mathrm{p}, \mathrm{xn}){ }^{103} \mathrm{Pd}$ nuclear process. Radiochim Acta 87: 87-91.

112. Smith-Jones PM, Strelow FWE, Haasbroek FJ, Bohmar RG (1988) Production of carrier free ${ }^{109} \mathrm{Cd},{ }^{57} \mathrm{Co}$ and ${ }^{54} \mathrm{Mn}$ from a composite cyclotron target of enriched silver-109 and iron-56. Appl Radiat Isot 39: 1073-1078.

113. Lahiri S, Nandy M, Mukhopadhyay B (1997) Sequential separation of carrier free radioisotopes of rhodium, silver and cadmium produced in a-particle activated palladium by TOA. Appl Radiat Isot 48: 1169-1172. 